\title{
An Integrated Approach to Teaching Price Discrimination
}

\author{
Ann Marsden and Hugh Sibly
}

\begin{abstract}
Textbooks present the three 'degrees' of price discrimination as a sequence of independent pricing methods and consequently provide inadequate insight as to when a firm might adopt a particular pricing strategy. The paper describes a taxonomy of the various mechanisms of price discrimination, which can be used to teach monopolistic price discrimination in an integrated way. The pricing strategy adopted by firms is based on (i) the information on consumer demand available to it and (ii) whether the firm has the ability to conduct non-linear pricing. The paper proposes a method for ranking profit and efficiency levels under different price discrimination strategies. The proposed taxonomy is compared to the existing textbook approach.
\end{abstract}

JEL classification: A20, A22, L11, L12

\section{Introduction}

Students observe price discrimination in their daily life. They could, for example, purchase bus tickets at a discounted 'student' rate. Such a purchase is contingent on providing evidence that they are a student (usually by producing their student cards). They will often also observe that both adult and student travellers must choose between various size bundles of bus tickets. Larger bundles mean cheaper prices per ticket. Although this is one transaction for the student they are in fact facing two different price discrimination mechanisms. Textbooks do not provide an integrated explanation for this pricing behaviour of firms. Rather they often still provide independent explanations of the three types of price discrimination (first, second and third degree price discrimination) first proposed by Pigou (1920). The technical treatments of each type of price discrimination are usually incompatible with one another, since first degree considers linear and non-linear prices, second degree non-linear prices, and third degree linear prices. Students are left to ponder how, if at all, these types of price discrimination might be related.

In this paper we propose an integrated method to teaching price discrimination. We present a taxonomy based on two characteristics of the market the firm faces: (i) whether there exists a costless exogenous signal of customer type (such as a student card) and (ii) whether it is possible for the firm to conduct non-linear pricing. This taxonomy allows students to identify the circumstances under which the firm would undertake a particular type of price discrimination.

Recent literature takes the view that the price discrimination strategy adopted by the firm is associated with the information on consumer type (demand) available to it. Varian (1987) provides an earlier overview of this literature, in particular of the self-selection mechanisms implicit in second degree price discrimination. More recently Stole (2007) provides an overview of price discrimination in the context of competitive markets. The approach in this recent literature makes the distinction between direct and indirect price discrimination. Direct price discrimination is based on observable consumer characteristics, for example whether a customer has a student card. Indirect price discrimination is when firms cannot observe consumer 
characteristics and so must use some pricing strategies to identify the customer type. This corresponds to the bus company offering students various bundle sizes to choose from.

The second market characteristic in our taxonomy relates to the ability of the firm to use nonlinear pricing. There may be a variety of reasons why firms use linear pricing (e.g. government regulation, high cost of bundling), but the easiest one to motivate students in a classroom is that the goods can be resold by customers. In this paper we draw the distinction between markets in which intra-type arbitrage is possible or those in which it is not possible (e.g. whether students can costlessly re-sell a bus ticket they bought to another student). The firm utilises linear pricing in the former case and non-linear pricing in the latter.

There are a number of papers related to the teaching of price discrimination. Carroll and Coates (1999) explore the teaching of price discrimination and consider the efficiency and profit gains under first, second and third degree price discrimination. They note that assessing whether a two-part tariff enables the firm to capture more consumer surplus than if it used third degree price discrimination is not generally determinable. A student considering the two types of price discrimination would therefore be unable to link the two conceptually from the analysis. Using the approach proposed in this paper enables the student to consider second and third degree price discrimination as part of a conceptually unified approach to price discrimination. In the comment and addendum to the Carroll and Coates (1999) paper Jeitschko (2001) has concerns about what is (or should) be taken away from the classroom after a discussion of price discrimination, especially regarding implications of price discrimination on economic efficiency. The approach we take allows the efficiency implications to be assessed for a particular price discrimination strategy. This means that efficiency can be compared across strategies.

Gotlibovski and Kahana (2009) note that the typical intermediate microeconomics textbook discusses only first and third degree price discrimination, because the presentation of second degree price discrimination requires the use of a more sophisticated mathematical technique. They note that Varian (2006) uses a simple diagram to explain second degree price discrimination. Gotlibovski and Kahana (2009) build on this diagram to explain differences between price quantity packages and two-part pricing. This paper uses a similar approach in proposing an information based analysis of direct and indirect price discrimination.

Our paper proceeds as follows. First we consider the existing textbook approach and how our approach differs from this approach. Then, we outline our assumptions regarding consumer demand. We then consider markets in which intra-type arbitrage is not possible, going on to identify the optimal non-linear pricing strategy given the market's information structure. Then the profitability and efficiency of each pricing strategy is ranked. This ranking is related to the information structure. We consider markets in which intra-type arbitrage is possible and consequently linear pricing must be used by firms. We relate the market outcome under linear pricing to that under non-linear pricing. Finally we bring together the analysis of the previous sections to present an integrated approach to teaching price discrimination, before concluding the paper.

\section{Existing textbook approaches}

A survey of five principles of microeconomics texts, Hubbard et al. (2009), McTaggart et al. (2010), Perloff (2009), Swann and McEachern (2003) and Taylor and Frost (2006), demonstrates that existing textbooks each use a mix of linear and non-linear pricing to demonstrate the three types of price discrimination with, in most cases, no attempt to link the different types of price discrimination. In the bus ticket example, the textbook explanation for the student discount is presented separately from the quantity discount for the bundle of tickets. The former is an example of third degree price discrimination and the latter an example of second degree price discrimination. Separating the analysis in texts offers little opportunity for the student to see 
these strategies as linked. The existing textbook treatments consequently provide little insight as to when a firm might adopt third degree price discrimination as opposed to second degree price discrimination or when a firm might use a mix of both types of price discrimination. Observation of firms indicates that in many cases they do not use either third or second degree price discrimination but approach their pricing using a mix of the two types of price discrimination. This is the case for the bus company discussed above. Similarly cinemas offer both student discounts and discounts for quantity. Accommodation providers offer both corporate and leisure rates, as well as discounts for extended stays. The framework we propose using non-linear pricing strategies readily models this behaviour.

In the textbooks, first degree price discrimination may be discussed in terms of customers buying either one unit or more than one unit. Where customers buy only one unit first degree price discrimination is presented using a linear market demand curve with each buyer having a different marginal benefit along the demand curve. The firm maximises profit (and incidentally social surplus) by charging each customer a price which exactly matches the marginal benefit of that customer. Where customers purchase more than one unit, first degree price discrimination is presented using non-linear pricing. It is common to see an analysis involving two consumers whose demand curves for the good differ. The firm maximises profit (and also social surplus again) by charging a tariff to each customer type equal to total benefit for the efficient quantity for that customer type (which occurs where the type's marginal benefit equals marginal cost). We use non-linear pricing to show that first degree price discrimination is a form of direct price discrimination where the firm has full information about each of its customers' characteristics.

In the textbooks third degree price discrimination is usually discussed in the context of linear pricing using the traditional Pigouvian approach. Textbooks generally consider two groups of customers whose market demand curves have different elasticities at all price levels. The firm is able to identify the group using a signal which provides information about the characteristics of that group. The firm sets the price to each group at the point where the marginal revenue of the group is equal to marginal cost. Pricing is linear since the firm sets a uniform price for each group. Customers may purchase only one unit or more than one unit but pay the same price per unit irrespective of the amount they purchase. The textbook treatment assumes that the firm sets a linear price because they have insufficient information to further separate customers within the groups. This issue is explored further later. We show that third degree price discrimination is a form of direct price discrimination where firms have some information about customer characteristics of groups and can be approached using non-linear pricing. We then incorporate the traditional Pigouvian textbook approach into our analysis.

The modern textbook treatment of second-degree price discrimination as shown in Tirole (1988) and Carlton and Perloff (2004) differs from that identified by Pigou (1920). There is some confusion regarding Pigou's original definition of second-degree price discrimination. Many recent writers include self-selection via non-linear pricing as a form of second degree price discrimination. Stole (2007) notes that Pigou (1920) did not consider second degree price discrimination as a selection mechanism, but rather thought of it as an approximation of first degree using a step function below the consumer's demand curve. As such, Pigou regarded both first and second degree price discrimination as 'scarcely ever practicable' and 'of academic interest only'.

The modern treatment of second degree price discrimination, beginning with Spence (1977) and Maskin and Riley (1984), utilises modern advances in information economics to explicitly model the information asymmetry between a firm and its customers. Whereas first or third degree price discrimination is used when observable customer characteristics are common knowledge, second degree price discrimination is used when the customer characteristics are private information (known only to the customer him or herself). Non-linear pricing schedules can then 
be used to provide customers with an incentive to self-identify. The modern textbook treatment usually follows this approach and we also use the same approach in this paper. These treatments generally consider two customer types, one of whose demand curve lies uniformly above the other. Non-linear prices are used to provide an incentive for customers to reveal their types. Examples of such non-linear pricing are abundant, so Pigou was incorrect in asserting that second-degree price discrimination is 'of academic interest only'. The student only has to observe prices per unit in the supermarket to see examples of non-linear prices. Many supermarket items are sold in different sized packages with the price per unit falling as the packet size increases. Similarly many coffee shops offer a free coffee after the buyer has purchased a minimum number of cups of coffee thus offering a lower price per unit for the purchaser of larger quantities. The bus ticket discount for purchases of larger quantities is also an example of second degree price discrimination.

Teaching and learning the three types of price discrimination using the mix of linear and nonlinear pricing methods proposed in the (inconsistent) Pigouvian taxonomy can be confusing. Textbooks do not generally link the linear and non-linear analytical approaches and may in fact avoid using the non-linear analysis of second degree price discrimination as noted by Gotlibovski and Kahana (2009) because of the mathematical difficulty. In contrast, by using an approach that systematically modifies the information available to the firm regarding the distribution of customer demands, and using linear and non-linear pricing in a systematic way, the optimal (discriminatory) pricing strategy available to firms can be identified. Thus the incentives for price discrimination are clearly identified in an integrated manner that allows students to view the firm's profit level as a function of the optimal mix of direct and indirect price discrimination strategies. Using this approach also allows the (Pigovian) third degree price discrimination linear analysis to be examined in the context of non-linear pricing. In fact we show that a firm has an incentive to use non-linear pricing rather than linear pricing where possible.

\section{Customer demand}

We start with the assumption that the firm, which is a monopoly, is aware of the distribution of customers' demand curves (and thus can calculate market demand), but it may not be able to costlessly associate a demand curve with a particular customer. It is also useful to restrict consideration to those cases in which demand curves of different customer types do not cross. This provides an unambiguous ranking of customers in terms of their willingness to pay, thus particular customer types can be identified as having a higher or lower demand than other customer types. This condition is known variously as 'uniform ordering', the 'sorting condition' the 'single crossing condition' or the 'Spence-Mirlees' condition' (Spence, 1977). The same demand curves can then be used throughout the analysis of direct and indirect price discrimination thereby providing students with a framework that is analytically self-contained.

We further restrict attention to the case in which there are three customer types. Discussions of price discrimination in the textbooks often consider only two customer types. However, to consider the examples of price discrimination discussed in the introduction, and to develop a conceptually encompassing information-based taxonomy, requires a minimum of three customer types. This approach is in the tradition set out in Goldman et al. (1984) and used by Dolan and Simon (1996). The analysis could be extended to more customer types but this yields little additional economic insight. Thus for ease of presentation we restrict consideration to three customer types.

Figure 1 illustrates the condition for three types of customers: Customers $\mathrm{H}$ (high demand), $\mathrm{M}$ (medium demand) and $\mathrm{L}$ (low demand). We will use the same demand curves throughout the analysis in the following sections. Note that under this condition type $\mathrm{H}$ customer's demand curve lies above type $M$ customer's demand curve, which itself lies above type $L$ customer's demand curve. Thus for any level of output, $\mathrm{q}_{0}$, as shown in Figure 1, the marginal valuation of 
type $\mathrm{H}$ customers $\left(\mathrm{P}_{\mathrm{H}}^{0}\right)$ is greater than the marginal valuation of type $\mathrm{M}$ customers $\left(\mathrm{P}_{\mathrm{M}}^{0}\right)$ which is greater than the marginal valuation to type $L$ customers $\left(P_{L}^{0}\right)$. Consequently type $H$ customers have a higher total valuation than type $M$ customers, who have a higher total valuation than type L customers. We illustrate our analysis throughout this section using the bus ticket example introduced earlier. Using this example an instructor could assume that high demand adult customers using the bus (e.g. commuters) are type $\mathrm{H}$ customers, lower demand adult customers (non-commuters) are type $\mathrm{M}$ customers and student customers the type L customers. We also provide a numerical example later and have annotated this example with the notation used in this section. This means that an instructor could use either the algebraic or numerical model (or both) to demonstrate this integrated approach to teaching price discrimination.

Figure 1 Demand curves satisfying uniform ordering and tariffs under first degree price discrimination

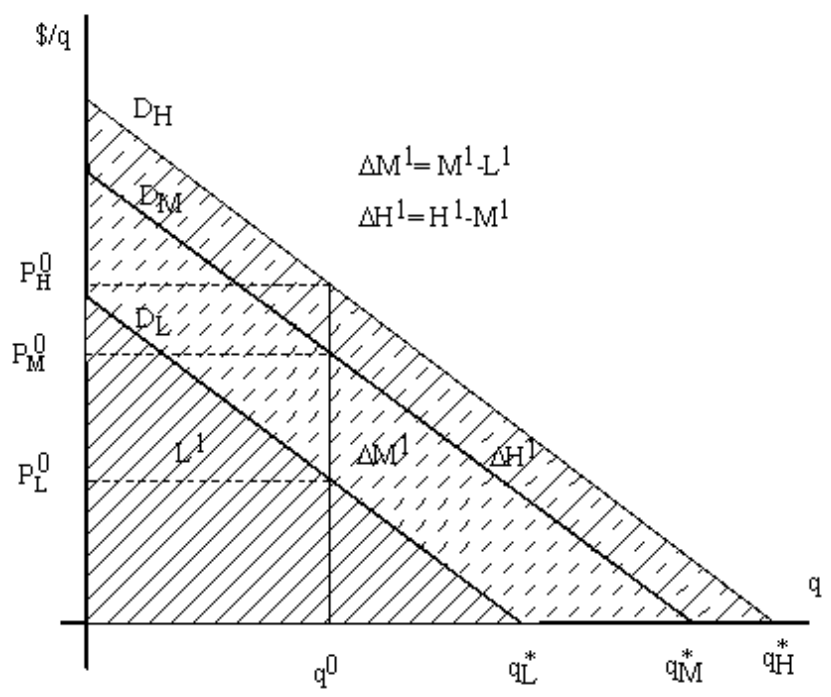

\section{Non-linear pricing: no intra-type arbitrage}

In this section it is assumed that it is not possible for customers of a given type to trade (i.e. resell) the firm's output amongst themselves. ${ }^{1}$ In this case the firm can bundle its output and each must consume one of the bundles offered by the firm (or otherwise consume nothing of the good). The pricing strategy adopted by the firm depends on how readily it can identify customers as belonging to the different types. Below we consider the cases in which, (i) the firm can costlessly identify each customer's type, (ii) can costlessly identify only one type of customer, (iii) cannot identify any customer's type. We will assume for simplicity that marginal cost for the firm is equal to zero.

\section{Pure direct non-linear pricing: all customer types costlessly identified}

We will start by considering the case where a given customer's type is common knowledge, and thus firms can costlessly identify and separate the three customer types. This is a form of direct price discrimination and corresponds to Pigouvian first degree price discrimination in the

\footnotetext{
${ }^{1}$ Inter-type trade is ruled out throughout this paper. An example of inter-type trade would be a student reselling a bus ticket to a non-student for a profit. An example of intra-type arbitrage would be a student unbundling a bundle of 10 tickets and selling single tickets to other students for a profit. If intra-group arbitrage is possible but not inter-type arbitrage then the firm must offer a linear price to each group. If both types of arbitrage are possible then the firm must offer a common linear price to all groups.
} 
textbooks. The firm can capture all the consumer surplus of each customer type by offering each customer a block tariff.

The optimal pricing structure in this case is shown in Figure 1. Type $L$ customers are offered schedule $\left\langle q_{L}^{*}, L^{1}\right\rangle$, which consists of a bundle of q $q_{L}^{*}$ units for tariff equal to $L^{1}$. This schedule leaves the consumer with zero consumer surplus, so the customer is indifferent between purchasing the bundle or not purchasing it. For ease of analysis assume that the customer purchases the bundle when indifferent. Similarly type $M$ customers are offered the schedule $\left\langle q_{M}^{*}, M^{1}\right\rangle$ where $M^{1}=L^{1}+\Delta M^{1}$ and type $H$ are offered the schedule $\left\langle q_{H}^{*}, H^{1}>\right.$ where $H^{1}=M^{1}+\Delta H^{1}$. The number of type $H$ customers is $N_{H}$, the number of type $M$ customers is $N_{M}$ and the number of type $L$ customers is $\mathrm{N}_{\mathrm{L}}$. Profit, using the notation $\Pi$, is equal to:

$$
\Pi^{1}=N_{L} L^{1}+N_{M} M^{1}+N_{H} H^{1}
$$

Note that each customer purchases the efficient quantity. Using the bus ticket example this means that both types of adult fare customers and the student fare customers each pay a price that exactly matches the total benefit they receive from purchasing their bundle of tickets. The adult commuter customers purchase the largest bundle, the adult non-commuter customers the next largest bundle and the student customers the smallest bundle.

\section{Partial direct non-linear pricing: one customer type costlessly identified}

Next assume the firm can costlessly identify (and thus separate) type L customers. However it cannot costlessly distinguish between type $\mathrm{M}$ customers and type $\mathrm{H}$ customers. The profit maximising pricing strategy requires the firm to separate customers according to the freely available information. In particular each identifiable group of customers potentially contains within it customers with heterogenous demands, e.g. type $\mathrm{M}$ and type $\mathrm{H}$.

The firm has to set a schedule that ensures type $M$ and type $H$ customers self-select the appropriate bundle. Figure 2 shows how the non-linear pricing can be used by the firm to profitably separate the type $\mathrm{M}$ and type $\mathrm{H}$ customers.

Figure 2 Partial direct non-linear pricing

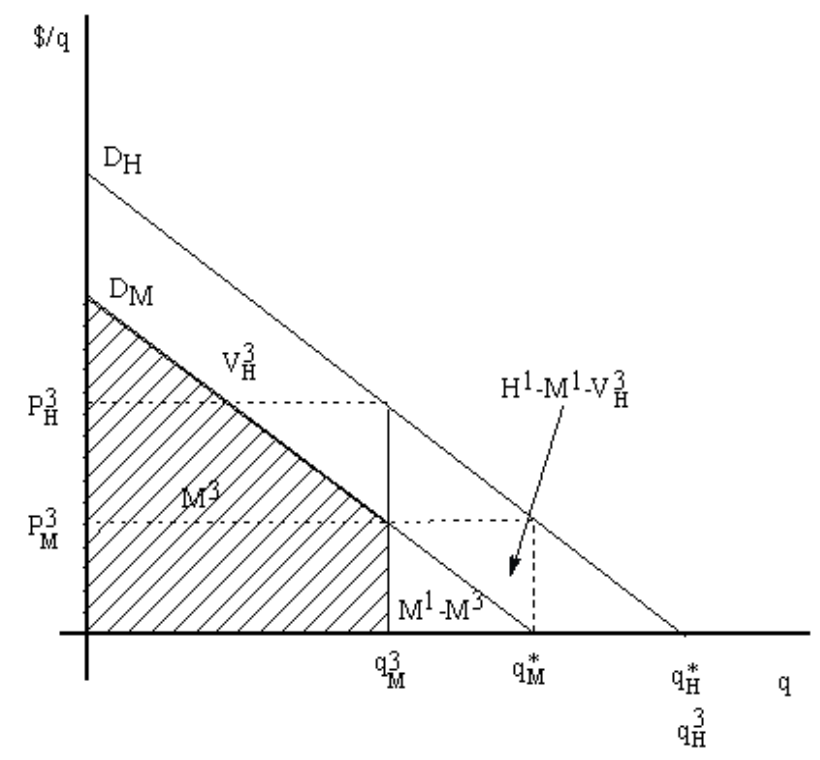


The firm offers two schedules $\left\langle\mathrm{q}_{M}^{3}, \mathrm{M}^{3}\right\rangle$ and $\left\langle\mathrm{q}_{\mathrm{H}}^{3}, \mathrm{H}^{3}\right\rangle$. The former schedule is directed at type $\mathrm{M}$ customers and the latter type $\mathrm{H}$ customers. It is profit maximising for the firm to extract the entire consumer surplus from type $\mathrm{M}$ customers. Self-selection requires that the type $\mathrm{H}$ customers not purchase the schedule $\left\langle\mathrm{q}_{\mathrm{M}}^{3}, \mathrm{M}^{3}\right\rangle$. This means that the high demand customers must be guaranteed a consumer surplus $\mathrm{V}_{\mathrm{H}}^{3}$. The maximum consumer surplus the firm can extract from type $H$ customers given this self-selection constraint occurs when $\mathrm{q}_{\mathrm{H}}^{3}=\mathrm{q}_{\mathrm{H}}^{*}$ and $\mathrm{H}^{3}=\mathrm{H}^{1}-\mathrm{V}_{\mathrm{H}}^{3}$.

The firm's problem is then to choose the profit maximising level of $\mathrm{q}_{\mathrm{M}}^{3}$. Note that as the firm reduces $q_{M}^{3}$ by one unit the revenue from the tariff paid by type $M$ customers reduces by $N_{M} P_{M}^{3}$, as $P_{M}^{3}$ is the marginal valuation of type $M$ customers. At the same time the tariff paid by type $H$ customers can be increased by $\mathrm{N}_{\mathrm{H}}\left(\mathrm{P}_{\mathrm{H}}^{3}-\mathrm{P}_{\mathrm{M}}^{3}\right)$ and still satisfy self selection. The profit maximising level of $q_{M}^{3}$ satisfies $N_{M} P_{M}^{3}=N_{H}\left(P_{H}^{3}-P_{M}^{3}\right)$. Firm profit is thus given by:

$$
\Pi^{3}=N_{L} L^{1}+N_{M} M^{3}+N_{H}\left(H^{1}-V_{H}^{3}\right)
$$

where $M^{3}<H^{1}-V_{H}^{3}$. The deadweight loss is given by $N_{M}\left(M^{1}-M^{3}\right)$.

Note that if $N_{M} P_{M}^{3}<N_{H}\left(P_{H}^{3}-P_{M}^{3}\right)$ for all $q$, then it is profit maximising to set $q_{M}^{3}=0$. This can happen in two ways:

(i) the ratio of $\mathrm{P}_{\mathrm{H}}^{3}$ to $\mathrm{P}_{\mathrm{M}}^{3}$ may be sufficiently high;

(ii) the ratio of $\mathrm{N}_{H}$ to $\mathrm{N}_{M}$ may be sufficiently high.

In this case the firm offers only one schedule to type $\mathrm{M}$ and $\mathrm{H}$ customers: $\left\langle\mathrm{q}_{\mathrm{H}}^{*}, \mathrm{H}^{1}\right\rangle$. This bundle is purchased only by type $H$ customers. If, on the other hand, $N_{M} P_{M}^{3}>N_{H}\left(P_{H}^{3}-P_{M}^{3}\right)$ for $q=0$ it must be the case that $\mathrm{q}_{\mathrm{M}}^{3}>0$. In this case the firm offers two schedules as described above.

Two variants of the information structure assumed above can be readily analysed: (i) the firm can costlessly separate type $M$ customers from type $L$ and type $H$ customers, but cannot distinguish between type $L$ and type $H$ customers and (ii) the firm can costlessly separate type $H$ from type $L$ and type $M$ customers, but cannot distinguish between type $L$ and type $M$ customers. The analysis of these information structures is analogous to the analysis above.

The methodology used in this subsection can be used when the firm has incomplete information on customer types. In these cases the firm maximises profit by firstly using costlessly available information to separate its customers into groups (direct price discrimination) and then further separating these groups into sub-groups of uniform type using the non-linear pricing schedules as a screening method (indirect price discrimination). Within the groups the customers with the highest demand receive a positive consumer surplus and lower demand customers buy a bundle with inefficient quantity. By offering the lower demand customers an inefficient quantity the lower demand bundles becomes less of a substitute for the highest demand bundle.

In the bus ticket example adult commuter customers purchase the same number of tickets as they did when the company could identify their customer type whereas adult non-commuter customers purchase a smaller number of tickets than they did when the company could identify their customer type. The adult commuter customers now pay a lower price per ticket and the adult non-commuter customers a higher price per ticket. The student customers pay the same price per ticket and purchase the same number of tickets as before since the company can still costlessly identify this customer type. 


\section{Pure indirect non-linear pricing: no customer types costlessly identified}

Finally consider the case in which the firm cannot costlessly identify and separate any of the three customer types. In this case the firm does not have the option of using exogenously provided information (such as a student card) to separate customers, but must devise a pricing strategy that identifies a customer type through self-selection. The optimal pricing strategy does this by using pricing schedules in the same way that it separated type $\mathrm{M}$ and type $\mathrm{H}$ customers above.

The determination of the optimal pricing structure is shown in Figure 3.

Figure 3 Pure indirect non-linear pricing

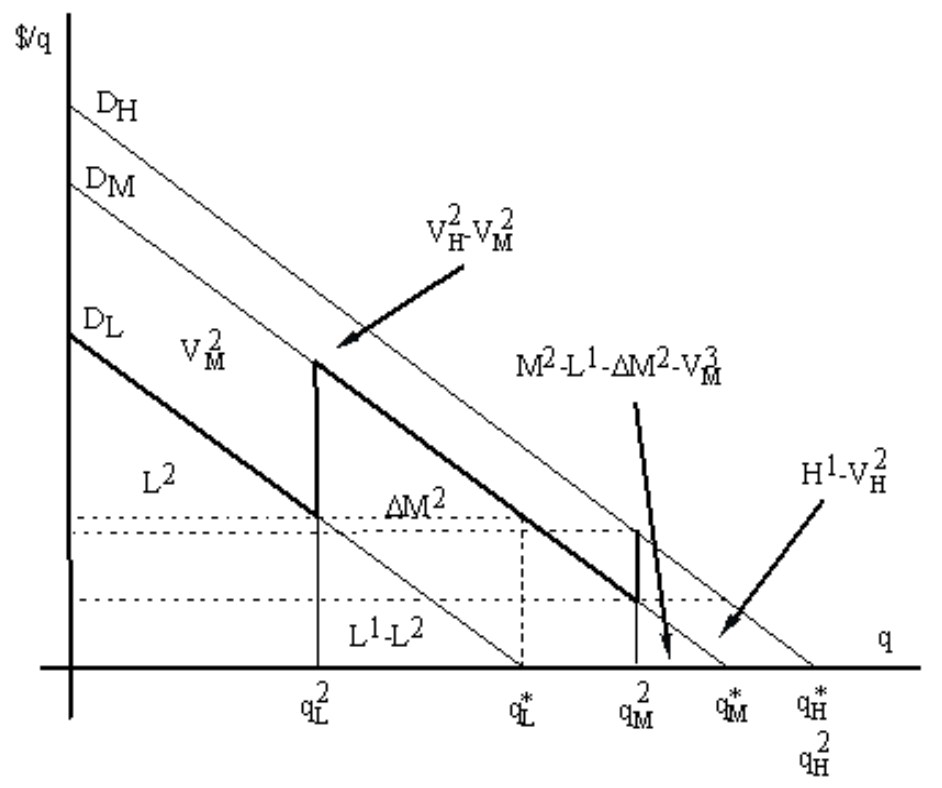

The firm offers three schedules $\left\langle\mathrm{q}_{\mathrm{L}}^{2}, \mathrm{~L}^{2}\right\rangle,\left\langle\mathrm{q}_{\mathrm{M}}^{2}, \mathrm{M}^{2}\right\rangle$ and $\left\langle\mathrm{q}_{\mathrm{H}}^{2}, \mathrm{H}^{2}\right\rangle$, directed at type $\mathrm{L}$, type $\mathrm{M}$ and type $\mathrm{H}$ customers respectively. It is profit maximising for the firm to extract the entire consumer surplus from type $L$ customers. Self-selection requires that the type $M(a n d H)$ customers not purchase the schedule $\left\langle q_{L}^{2}, L^{2}\right\rangle$. This means that the type $M$ customers must be guaranteed a consumer surplus $V_{M}^{2}$. The profit maximising level of $q_{L}^{2}$ satisfies $N_{L} P_{L}^{2}=N_{M}\left(P_{M}^{2}-P_{L}^{2}\right)$. At this point the revenue lost by reducing $\mathrm{q}_{\mathrm{L}}^{2}$ from type $\mathrm{L}$ customers $\left(\mathrm{N}_{\mathrm{L}} \mathrm{P}_{\mathrm{L}}^{2}\right)$ is just offset by the gain in revenue from type $M$ customers $\left(N_{M}\left(P_{M}^{2}-P_{L}^{2}\right)\right)$.

Self-selection requires that type $H$ customers do not purchase the schedule $\left\langle q_{M}^{2}, M^{2}\right\rangle$. This requires that type $\mathrm{H}$ customers be guaranteed a consumer surplus of $\mathrm{V}_{\mathrm{H}}^{2}$. The profit maximising level of $q_{M}^{2}$ satisfies $N_{M} P_{M}^{2}=N_{H}\left(P_{H}^{2}-P_{M}^{2}\right)$. At this point the revenue lost by reducing $q_{M}^{2}$ from type $M$ customers $\left(N_{M} P_{M}^{2}\right)$ is just offset by the gain in revenue from type $H$ customers $\left(N_{H}\left(P_{H}^{2}-P_{M}^{2}\right)\right)$. Hence $q_{M}^{2}=q_{M}^{3}$ and $V_{H}^{2}=V_{M}^{2}+V_{H}^{3}$. Note that if type $H$ customers do not purchase $\left\langle q_{M}^{2}, M^{2}\right\rangle$, they would not purchase $\left\langle\mathrm{q}_{\mathrm{L}}^{2}, \mathrm{~L}^{2}\right\rangle$ as it provides a lower consumer surplus.

As in the analysis in the previous section, it is optimal for the firm to set $\mathrm{q}_{\mathrm{H}}^{2}=\mathrm{q}_{\mathrm{H}}^{*}$ and to set a fee, $\mathrm{H}^{2}=\mathrm{H}^{1}-\mathrm{V}_{\mathrm{H}}^{2}$, which is just low enough to deter type $\mathrm{H}$ customers from switching to other bundles. 
In this case type L customers buy an inefficient quantity and keep no consumer surplus, type M customers buy an inefficient quantity and retain some consumer surplus and type $\mathrm{H}$ customers buy an efficient quantity and also retain some consumer surplus. Profit is now:

$$
\Pi^{2}=N_{L} L^{2}+N_{M}\left(M^{3}-V_{M}^{2}\right)+N_{H}\left(H^{1}-V_{M}^{2}-V_{H}^{3}\right)
$$

Type $\mathrm{H}$ customers buy the efficient quantity $\mathrm{q}_{\mathrm{H}}^{*}$, type $\mathrm{M}$ customers buy the inefficient quantity $\mathrm{q}_{\mathrm{M}}^{2}$ and type $L$ customers buy the inefficient quantity, $\mathrm{q}_{\mathrm{L}}^{2}$. The deadweight loss is given by $N_{M}\left(M^{1}-M^{3}\right)+N_{L}\left(L^{1}-L^{2}\right)$.

The above analysis was based on the assumption that $q_{M}^{2}>q_{L}^{2}$ where $q_{M}^{2}$ satisfies $N_{M} P_{M}^{2}=N_{H}\left(P_{H}^{2}-P_{M}^{2}\right)$ and $q_{L}^{2}$ satisfies $N_{L} P_{L}^{2}=N_{M}\left(P_{M}^{2}-P_{L}^{2}\right)$. Note that it is possible that these expressions yield values of $q_{M}^{2}$ and $q_{L}^{2}$ such that $q_{M}^{2}<q_{L}^{2}$. This would be possible if $N_{M}$ is relatively small compared with $\mathrm{N}_{\mathrm{L}}$ and $\mathrm{N}_{\mathrm{H}}$. Clearly this outcome is not consistent with self-selection. In this case 'bunching' occurs. There is no separate bundle offered to type $M$, and both type $L$ and type $M$ customers purchase $\left\langle q_{L}^{2}, L^{2}\right\rangle$. In this case $q_{L}^{2}$ is determined by $\left(N_{L}+N_{M}\right) P_{L}^{2}=N_{H}\left(P_{H}^{2}-P_{M}^{2}\right)$.

In the bus ticket example this means the company can no longer identify any of the customer types. The adult commuter customers purchase the same number of tickets but pay a lower price per ticket than when the company could identify the student (and thus adult) customer type. The adult non-commuter customers purchase the same number of tickets but pay a lower price per ticket than when the company could identify the student (and thus adult) customer type. Finally the student customers purchase a smaller number of tickets and pay a higher price per ticket than when the company could identify them.

\section{Profit and efficiency ranking with non-linear pricing}

Since profit varies with the level of information that a firm has about its customers we can now show how to rank profit levels according to the information available to the firm. The firm makes the maximum possible profit when it can costlessly identify and separate each customer and offer them a non-linear price that captures their entire consumer surplus. Specifically profit is:

$$
\Pi^{1}=N_{L} L^{1}+N_{M} M^{1}+N_{H} H^{1}
$$

Profit is lower than this maximum when only one customer type rather than all customer types can be costlessly identified and separated. If only type $L$ customers can be costlessly identified and separated, profit is lower than $\Pi^{1}$ because (i) there is a lower fee paid by type M customers because they purchase only $\mathrm{q}_{M}^{3}$ (fee $\mathrm{M}^{3}$ ) rather than $\mathrm{q}_{M}^{*}$ (fee $\mathrm{M}^{1}$ ) and (ii) type $\mathrm{H}$ customers pay a lower fee of $\mathrm{H}^{1}-\mathrm{V}_{\mathrm{H}}^{3}$ rather than $\mathrm{H}^{1}$. Mathematically the difference in profit is:

$$
\Pi^{1}-\Pi^{3}=N_{M}\left(M^{1}-M^{3}\right)+N_{H} V_{H}^{3}
$$

The difference in profit is the information cost of separating type $M$ customers. The deadweight loss increases by $N_{M}\left(M^{1}-M^{3}\right)$.

Profit is even lower when no customer types rather than one customer type can be costlessly identified and separated for three reasons: (i) there is a lower fee paid by type $L$ customer because they purchase only $\mathrm{q}_{\mathrm{L}}^{2}\left(\right.$ fee $\mathrm{L}^{2}$ ) rather than $\mathrm{q}_{\mathrm{L}}^{*}\left(\right.$ fee $\mathrm{L}^{1}$ ); (ii) there is a lower fee paid by type $\mathrm{M}$ customers as they pay a fee of $\mathrm{M}^{3}-\mathrm{V}_{\mathrm{M}}^{2}$ rather than $\mathrm{M}^{3}$; and (iii) type $\mathrm{H}$ customers pay a lower fee of $H^{1}-V_{M}^{2}-V_{H}^{3}$ rather than $H^{1}-V_{H}^{3}$. Mathematically the difference in profit is:

$$
\Pi^{3}-\Pi^{2}=N_{L}\left(L^{1}-L^{2}\right)+N_{M} V_{M}^{2}+N_{H} V_{M}^{2}
$$


The difference in profit is the information cost of identifying and separating type $L$ customers. The deadweight loss increases by $\mathrm{N}_{\mathrm{L}}\left(\mathrm{L}^{1}-\mathrm{L}^{2}\right)$.

In summary, the less capable the firm in identifying a customer's type (and the more it must rely on self-selection), the lower is its profit. Thus the information on customer type can be viewed as a valuable commodity. The more the firm must rely on pricing strategies to reveal a customer's type the greater is the deadweight loss.

\section{Price discrimination with linear prices}

Having introduced students to direct and indirect price discrimination using non-linear pricing the student may well ask how this relates to the ubiquitous analysis of firms who use linear pricing? This question should be addressed. The answer is that firms use linear pricing when it is not possible to use non-linear pricing strategies. There are two important circumstances in which the firm would not use non-linear pricing. The first is where all customer types have unit demand, and the firm cannot identify an individual customer's type (i.e. their willingness to pay): for example, if all bus passengers had demand for only one bus ride, but all varied in their willingness to pay for that ride. In such instances the elasticity of demand depends on the distribution of customers' willingness to pay. (Third degree price discrimination could be practised if the firm could observe group types, and the groups differ in their distribution of willingness pay.) However in those cases in which non-linear pricing can be used, customers vary in the quantity they demand. To relate the analysis of non-linear pricing to linear pricing, it is useful to consider the second circumstance in which the firm will use linear pricing. That is, in the case in which the good can be (costlessly) resold. If the firm cannot prevent resale it must offer a linear price (i.e. a common price per unit) to all customers in order to prevent arbitrage between customers. If the firm did attempt to utilise non-linear pricing, bundles could be unpacked and sold at the average price of the good in the bundle. This price would become the linear market price. Thus, when the firm cannot prevent resale, it will not be able to avoid setting a linear price. For instance, if bus tickets were sold in a bundle of 10 for $\$ 10$, anyone could obtain a single ticket for $\$ 1$ if (costless) resale were possible. This would effectively be the linear market price the firm is setting.

As in the case of non-linear pricing the firm using linear pricing may have full, partial or no information on individual customer's type. Pigouvain third degree price discrimination occurs when there is both linear pricing (because of intra-group arbitrage) and when the firm observes some exogenous information as to a customer's type.

Figure 4: Price discrimination with linear prices

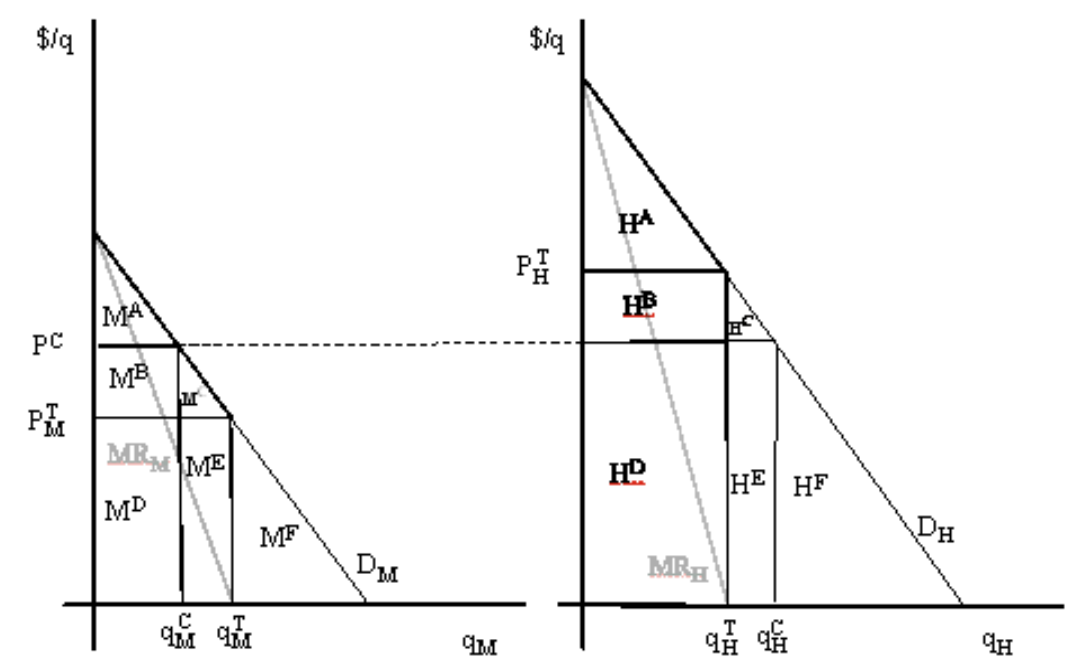


Figure 4 casts textbook (Pigouvian) third degree price discrimination in a manner that facilitates comparison with the above analysis of non-linear pricing. For brevity we present the detailed analysis with only two customer types (the minimum number of types needed to consider the implications), which are labelled $\mathrm{M}$ and $\mathrm{H}$.

If the firm cannot identify a particular customer's type, and intra-group arbitrage is possible, it must set a common linear price. This is the case of a simple monopoly. The profit maximising, common linear price is shown as $P^{C}$, and the firm maximum profit when the firm cannot identify customer type is thus:

$$
\Pi^{C}=N_{M}\left(M^{B}+M^{D}\right)+N_{H}\left(H^{D}+H^{E}\right)
$$

The deadweight loss is: $N_{M}\left(M^{C}+M^{E}+M^{F}\right)+N_{H} H^{F}$.

Now consider the case in which the firm can costlessly identify customers by their type, and intra-group (but not inter-group) arbitrage is possible. The usual textbook examples of student discount on cinema tickets and geographical separation satisfy this requirement. The linear price $P_{M}^{\top}$ is charged to type $M$ customers, who purchase quantity $q_{M}^{\top}$, and the linear price $P_{H}^{\top}$ is charged to type $\mathrm{H}$ customers, who purchase quantity $\mathrm{q}_{\mathrm{H}}^{\top}$. The firm's profit is:

$$
\Pi^{\top}=N_{M}\left(M^{D}+M^{E}\right)+N_{H}\left(H^{B}+H^{D}\right)
$$

The deadweight loss is: $\mathrm{N}_{M} M^{F}+N_{H}\left(H^{C}+H^{E}+H^{F}\right)$.

In the bus ticket example the commuter customer can purchase any number of tickets but pays the same price per ticket irrespective of the number of tickets purchased. Likewise the noncommuter customer can purchase any number of tickets but also pays the same price per ticket irrespective of the number of tickets purchased. The commuter however pays a higher price per ticket than the non-commuter if the former has a lower elasticity of demand (which we might expect to be the case for those with 'high' demand).

The impact of the move from common linear pricing to third degree (linear) price discrimination changes profit by:

$$
\Delta \Pi=N_{M}\left(M^{E}-M^{B}\right)+N_{H}\left(H^{B}-H^{E}\right)
$$

as type $H$ has inelastic demand and type $M$ has elastic demand $\Delta \Pi>0$. Thus the firm is able to utilise the information identifying customer type to increase its profit. This result is consistent with the analysis above. ${ }^{2}$

\footnotetext{
${ }^{2}$ Note that the firm would prefer to use a non-linear price rather than a linear price. This is demonstrated by showing that the firm can increase profit by switching to a non-linear price from a linear price. If the firm could prevent resale (and thus profitably conduct non-linear pricing), it could sell a bundle consisting of $q_{M}^{c}$ to type $M$ customers for a fee of $M^{A}+M^{B}+M^{D}$, and sell a bundle of $q_{H}^{C}$ to type $H$ customers for a fee of $M^{A}+H^{D}+H^{E}$. This strategy increases the profit per customer by $M^{A}$ and additionally satisfies self-selection. Hence using non-linear pricing increases profit relative to linear pricing. Of course the firm can maximise profits by adopting the pricing described above (Figure 2). We thus assume that the firm is exogenously forced to set a linear price so that we can compare textbook treatments of third degree price discrimination with the above analysis.
} 
However, in contrast to the above analysis, deadweight loss does not reduce as firms are provided with additional information. Specifically, if the firm moves from common linear pricing to third degree (linear) price discrimination the deadweight loss increases by:

$$
N_{H}\left(H^{C}+H^{E}\right)-N_{M}\left(M^{C}+M^{E}\right)
$$

This expression is negative when demand curves are linear and output is unchanged but may not be negative in other cases. Robinson (1933) showed that the movement toward third degree discriminating prices alters the distribution of output but does not change total output when demand curves are linear. Schmalensee (1981) showed that deadweight loss increases unless output increases. Thus, when demand curves are linear, the implementation of third degree price discrimination increases deadweight loss. Ikeda and Toshimitsu (2010), using a model in which consumers have unit demand and quality is endogenous, show that an increase in total output is a necessary condition for welfare improvement with third degree price discrimination by a monopolist. This is apparent from Figure 4 once it is realised that with linear demand curves $N_{M}\left(q_{M}^{\top}-q_{M}^{C}\right)$ must equal $N_{H}\left(q_{H}^{C}-q_{H}^{\top}\right)$.

Thus, when output does not increase, the provision of information on customer type that allows the firm to implement third degree price discrimination lowers welfare. This conclusion, implicit in textbook treatments, is the opposite of the result presented above. The source of the divergence in the conclusion is due to the use (by the Pigouvian taxonomy) of linear pricing rather than non-linear pricing. This results in the firm reducing output to the type $\mathrm{H}$ customers in an attempt to capture their consumer surplus. The output supplied to type $\mathrm{M}$ customers however increases. This result contrasts to that obtained above for non-linear pricing, where output supplied to type $\mathrm{M}$ customers decreases due to implementation of price discrimination. By comparison Ikeda and Toshimitsu (2010) show that third degree price discrimination always enhances welfare when quality is endogenous, mainly because of the quality improvement owing to price discrimination increases consumer surplus.

Thus the conclusions derived from the textbook analysis of (Pigouvian) third degree price discrimination follows from the joint assumptions of linear pricing (i.e. intra-group arbitrage but no inter-group arbitrage) and the availability of an exogenous signal on customer types (or groups of types). The above analysis can be readily extended to the case of three customer types. In this event, as with non-linear pricing there are three possibilities:

(i) pure direct linear pricing in which each type faces their own linear price;

(ii) partial direct linear pricing in which the firm observes an exogenous signal about one type (which we take to be type $L$ ) and cannot distinguish between the other two types $(H$ and $M)$ : in this case the firm charges one linear price to the type with the exogenous signal (type $\mathrm{L}$ ) and a common price to the types that cannot be separated ( $\mathrm{H}$ and $\mathrm{M}$ ); and (iii) common linear pricing in which the firm cannot distinguish between all three customer types.

Using the above analysis it is readily demonstrated that the profit of the firm falls as the number of types it can identify falls (i.e. profits fall as we move from case (i) to (ii) and from (ii) to (iii)). Thus the firm will utilise exogenous signals on customer types whenever it is available.

\section{An integrated view}

The analysis above can be brought together to provide an integrated view of the firm's pricing strategy. This is summarised in Table 1. 
Table 1: Matrix of price discrimination options available for the firm

\begin{tabular}{llcc}
\hline \multicolumn{1}{c}{} & \multicolumn{2}{c}{ Intra-group arbitrage } \\
& Perfect & Not possible & Possible \\
\cline { 2 - 3 } Information on & Partial & Pure Direct, non-linear & Direct, linear \\
customer type & None & Partial Direct, non-linear & Partial Direct, linear \\
& & Pure Indirect, nonlinear & Common linear price \\
\hline
\end{tabular}

The firm faces two exogenous factors in the market environment when setting pricing. The first is whether it can costlessly utilise some exogenous signal to identify customers by their type. The second is whether customers can undertake intra-group arbitrage. (Note if inter-group arbitrage is also possible then the firm must use a common linear price.) The table indicates the pricing strategies adopted in the six market environments. The analysis above indicates that the firm's profit falls as we move either down or across the table. Thus firms always have an incentive to bundle output when possible and utilise available signals of customer types. Note that, as pointed out by Carroll and Coates (1999), it is not possible to tell whether profits are larger under pure indirect non-linear pricing (second degree price discrimination in textbooks) and direct linear pricing (third degree price discrimination in textbooks). However making this comparison is misleading for students. If the firm could conduct non-linear pricing and could identify customers by type, it would be better off using direct non-linear pricing.

Many students will benefit from seeing a numerical example of the model described above. The results of a numerical simulation are presented in Table 2 .

Table 2: Numerical simulation of price discrimination strategies

\begin{tabular}{|c|c|c|c|c|c|c|c|c|c|c|}
\hline & \multicolumn{4}{|c|}{ Quantity } & \multicolumn{2}{|c|}{ Price per unit } & \multicolumn{4}{|c|}{ Profit } \\
\hline & $\mathrm{q}_{\mathrm{H}}$ & $\mathrm{q}_{\mathrm{M}}$ & $q_{L}$ & $\overline{\mathrm{P}}_{\mathrm{H}}$ & $\overline{\mathrm{P}}_{\mathrm{M}}$ & $\overline{\mathrm{P}}_{\mathrm{L}}$ & $\Pi_{H}$ & $\Pi_{M}$ & $\Pi_{\mathrm{L}}$ & $\Pi$ \\
\hline $\begin{array}{l}\text { Pure direct, } \\
\text { non-linear }\end{array}$ & 20 & 18 & 16 & 10 & 9 & 8 & $\begin{array}{l}200 \\
\left(=\mathrm{H}^{1}\right)\end{array}$ & $\begin{array}{l}162 \\
\left(=M^{1}\right)\end{array}$ & $\begin{array}{l}128 \\
\left(=L^{1}\right)\end{array}$ & 490 \\
\hline $\begin{array}{l}\text { Partial direct, } \\
\text { non-linear }\end{array}$ & 20 & 16 & 16 & 8.4 & 10 & 8 & $\begin{array}{l}168 \\
\left(=H^{3}\right)\end{array}$ & $\begin{array}{l}1600 \\
\left(=M^{3}\right)\end{array}$ & $\begin{array}{l}1280 \\
\left(=L^{1}\right)\end{array}$ & 456 \\
\hline $\begin{array}{l}\text { Pure indirect, } \\
\text { non-linear }\end{array}$ & 20 & 16 & 12 & 7.2 & 8.5 & 10 & $\begin{array}{l}144 \\
\left(=\mathrm{H}^{2}\right)\end{array}$ & $\begin{array}{l}136 \\
\left(=M^{2}\right)\end{array}$ & $\begin{array}{l}120 \\
\left(=L^{2}\right)\end{array}$ & 400 \\
\hline Direct, linear & 10 & 9 & 8 & 10 & 9 & 8 & 100 & 81 & 64 & 245 \\
\hline $\begin{array}{l}\text { Partial direct, } \\
\text { linear }\end{array}$ & 10.5 & 8.5 & 8 & 9.5 & 9.5 & 8 & 99.75 & 80.75 & 64 & 244.5 \\
\hline $\begin{array}{l}\text { Common linear } \\
\text { price }\end{array}$ & 11 & 9 & 7 & 9 & 9 & 9 & 99 & 81 & 63 & 243 \\
\hline
\end{tabular}


Table 2 (cont.): Numerical simulation of price discrimination strategies

\begin{tabular}{|c|c|c|c|c|c|c|c|c|}
\hline & \multicolumn{4}{|c|}{ Consumer surplus } & \multicolumn{4}{|c|}{ Deadweight loss } \\
\hline & $\mathrm{CS}_{\mathrm{H}}$ & $\mathrm{CS}_{\mathrm{M}}$ & $\mathrm{CS}_{\mathrm{L}}$ & CS & $\mathrm{DWL}_{H}$ & $\mathrm{DWL}_{\mathrm{M}}$ & $\mathrm{DWL}_{\mathrm{L}}$ & DWL \\
\hline $\begin{array}{l}\text { Pure direct, } \\
\text { non-linear }\end{array}$ & 0 & 0 & 0 & 0 & 0 & 0 & 0 & 0 \\
\hline $\begin{array}{l}\text { Partial direct, } \\
\text { non-linear }\end{array}$ & $\begin{array}{c}32 \\
\left(=V_{H}^{3}\right)\end{array}$ & 0 & 0 & 32 & 0 & 2 & 0 & 2 \\
\hline $\begin{array}{l}\text { Pure indirect, } \\
\text { non-linear }\end{array}$ & $\begin{array}{c}56 \\
\left(=V_{H}^{2}\right)\end{array}$ & $\begin{array}{c}24 \\
\left(=V_{M}^{2}\right)\end{array}$ & 0 & 80 & 0 & 2 & 8 & 10 \\
\hline Direct, linear & 50 & 40.5 & 32 & 122.5 & 50 & 40.5 & 32 & 122.5 \\
\hline $\begin{array}{l}\text { Partial direct, } \\
\text { linear }\end{array}$ & 55.125 & 36.125 & 32 & 123.25 & 45.125 & 45.125 & 32 & 122.25 \\
\hline $\begin{array}{l}\text { Common } \\
\text { linear price }\end{array}$ & 60.5 & 40.5 & 24.5 & 125.5 & 40.5 & 40.5 & 40.5 & 121.5 \\
\hline
\end{tabular}

In this simulation it is assumed that $\mathrm{V}_{\mathrm{i}}(\mathrm{q})=\mathrm{q}\left(\mathrm{a}_{\mathrm{i}} \mathrm{q} / 2\right)$, where $\mathrm{a}_{\mathrm{H}}=20, \mathrm{a}_{\mathrm{M}}=18$ and $\mathrm{a}_{\mathrm{L}}=16$, and $\mathrm{N}_{\mathrm{H}}=\mathrm{N}_{\mathrm{M}}=\mathrm{N}_{\mathrm{L}}=10$. The table allows a comparison across pricing strategies of the quantity sold to each type $\left(q_{i}\right)$, the price per unit paid by each type $\left(\overline{P_{i}}\right)$, e profit generated by each type $\left(\Pi_{i}\right)$, total profit $(\Pi)$, consumer surplus obtained by each type $\left(\mathrm{CS}_{\mathrm{i}}\right)$, total consumer surplus (CS), deadweight loss associated with each type ( $\left.D W L_{i}\right)$ and total deadweight loss (DWL). There are numerous effects illustrated by this example, and the instructor can emphasise particular effects as appropriate. However in this table one can clearly see the benefit to the firm from an exogenous signal about customer type, and from the ability to conduct non-linear pricing. The impact of the presence of exogenous customer information on consumer surplus and deadweight loss is also illustrated.

\section{Conclusions}

When a market consists of more than one customer type a firm can potentially maximise its profits by charging different types different prices. We present a taxonomy that can make it clear to students that the ability of the firm to realise these prospective profits depends on (i) the information it has on customers and (ii) the ability of the firm to use non-linear pricing (specifically the absence of intra-group arbitrage). This approach demonstrates to students that information on customer types is valuable to firms. When a given customer's type is private information the firm can use non-linear pricing schedules to provide customers with an incentive to reveal their type. However, our approach demonstrates how extracting this information comes at a cost to the firm: profit is lower than would be the case if customers' types were common information. In addition we provide a method of demonstrating to students how the optimal screening method distorts the quantity available to low demand customers and thus generates a deadweight loss. When the firm cannot use non-linear pricing (i.e. when intra-group arbitrage is present) the firm cannot use a pricing mechanism to identify a given customer's type, and its profit consequently suffers.

We have presented an integrated approach to teaching the theory of price discrimination. This approach allows for a more coherent understanding of the different strategies adopted by firms. It emphasises that firms use price discrimination strategies as a means of maximising profit given the constraints imposed by their market's characteristics. This approach enables a straightforward explanation of the pricing strategies used by firms in many common real world examples. 


\section{References}

Carlton, D. and Perloff, J. (2004). Modern Industrial Organization, Sydney: The Addison-Wesley Series in Economics.

Carroll, K. and Coates, D. (1999). 'Teaching price discrimination: Some clarification', Southern Economic Journal, vol. 66(2), pp. 466-80.

Dolan, R. J. and Simon, H. (1996). Power Pricing: How Managing Price Transforms the Bottom Line, New York: The Free Press.

Goldman, M.B., Leland H.E. and Sibley, D.S. (1984). 'Optimal nonuniform pricing', The Review of Economic Studies, vol. 51(2), pp. 305-19.

Gotlibowski, C. and Kahana, N. (2009). 'Second-degree price discrimination: A graphical and mathematical approach', Journal of Economic Education, vol. 40(1), pp. 68-79.

Hubbard, R.G. et al. (2009). Microeconomics, Frenchs Forest NSW: Pearson Education Australia.

Ikeda, T. and Toshimitsu, T. (2010). 'Third degree price discrimination, quality choice, and welfare', Economic Letters, 106, pp. 54-6.

Jeitschko, T.D. (2001). 'Issues in price discrimination: A comment on and addendum to "Teaching price discrimination: Some clarification” by Carroll and Coates', Southern Economic Journal, vol. 68(1), pp. 178-86.

McTaggart, D. et al. (2010). Microeconomics, Frenchs Forest NSW: Pearson Education Australia.

Maskin, E. and Riley, J. (1984). 'Monopoly with incomplete information', RAND Journal of Economics, vol. 15(2), pp. 171-96.

Perloff, J.M. (2009). Microeconomics, Boston Massachusetts: Pearson Education, Inc.

Pigou, A. C. (1920). The Economics of Welfare, London: Macmillan.

Robinson, J. (1933). The Economics Of Imperfect Competition, London: Macmillan.

Schmalensee, R. (1981). ‘Output and welfare implications of monopolistic third-degree price discrimination', American Economic Review, vol. 71(1), pp. 242-7.

Spence, A. M. (1977). 'Nonlinear prices and welfare', Journal of Public Economics, vol. 8, pp. 1-18.

Stole, L. (2007). 'Price Discrimination and Competition', in (M. Armstrong and R. Porter, eds), Handbook of Industrial Organization, Volume 3, North-Holland: Elsevier.

Swann, M. and W.A. McEachern. (2003). Microeconomics. A Contemporary Introduction, Southbank Victoria: Thomson.

Taylor, J.B. and Frost, L. (2006). Microeconomics, Milton Queensland: John Wiley and Sons.

Tirole, J. (1988). The Theory of Industrial Organization, Cambridge: The MIT Press.

Varian, H. (1987). 'Price Discrimination', in (R. Schmalensee and R. Willig, eds), Handbook of Industrial Organization, Volume 2, North-Holland: Elsevier.

Varian, H. (2006). Intermediate Microeconomics: A Modern Approach, New York and London: W.W. Norton \& Company. 


\section{Author Biography}

Ann Marsden is currently lecturer with the Greenwich School of Management. Ann previously held the position of lecturer with the School of Economics and Finance, University of Tasmania. Her research and teaching interests are in the industrial economics area with a particular focus on pricing. She has also worked as an economist with London Underground and holds an MSc (Economics) from Birkbeck College. She has recently submitted her Doctoral thesis from the University of Tasmania.

Hugh Sibly is a senior lecturer in the School of Economics and Finance, University of Tasmania. He teaches in the areas of industrial organisation, game theory and macroeconomics. His areas of research interest include pricing in macroeconomics, utility pricing, industrial organisation and behavioural economics. Hugh is also a member of the Australian Copyright Tribunal. He received his PhD from the University of Melbourne.

\section{Contact details}

Ann Marsden

Greenwich School of Management

Royal Hill

London

SE10 8RD

United Kingdom

Tel: +44 (0)20 72548214

Hugh Sibly

University of Tasmania

Churchill Avenue

Sandy Bay

TAS 7005

Australia

Tel: +61362262825

Email: Hugh.Sibly@utas.edu.au 